Research Journal of Applied Sciences, Engineering and Technology 16(1): 24-29, 2019

DOI:10.19026/rjaset.16.5995

ISSN: 2040-7459; e-ISSN: 2040-7467

(C) 2019 Maxwell Scientific Publication Corp.

Submitted: September 10, 2018

Accepted: November 15, 2018

Published: January 15, 2019

\title{
Research Article \\ Model Tests on Single Batter Piles Subjected to Lateral Soil Movement
}

\author{
${ }^{1,2}$ Osamah Al-Salih, ${ }^{1}$ T. T. Sabbagh, ${ }^{1,2}$ Wisam Alawadi and ${ }^{2}$ I.Q. Al-abboodi \\ ${ }^{1}$ University of Salford, Salford, M5 4WT, UK \\ ${ }^{2}$ Department of Civil Engineering, University of Basrah, Iraq
}

\begin{abstract}
A series of laboratory tests have been carried out to investigate the lateral response of battered piles under lateral soil movement. Model tests were carried out using instrumented rigid aluminium piles. The piles were embedded in homogeneous sand soil at batter angles $\beta=0^{\circ}, \pm 10^{\circ}$ and $\pm 20^{\circ}$ were subjected to two types of lateral soil movement profile. The results obtained from the study are presented in terms of the bending moment, shear force, soil reaction, pile rotation and lateral deflections along the length of the batter pile. The results of model tests on single vertical and batter piles under horizontal loads showed that the batter angle $(\beta)$ significantly influenced the response of the batter piles. Regardless of the value of sand density, bending moment and deflection with batter angles $\beta=+10^{\circ}$ or positive batter piles were higher compared then vertical piles and negative batter piles.
\end{abstract}

Keywords: Batter angle, batter piles, pile deflection, soil movement, soil reaction

\section{INTRODUCTION}

Effect of soil displacement on pile foundation nearby is of great importance in geotechnical projects such as tunnelling, pit excavation, surcharge load and slope engineering. Inclined piles are widely used in these projects due to the superior capability for resisting lateral load.

Analyses of laterally loaded piles of various stiffnesses in homogeneous elastic soils indicate that free head piles may be considered as a rigid for practical purposes if their relative stiffness $\mathrm{Kr} \geq 0.01$ and flexible piles if their relative stiffness $\mathrm{Kr} \leq 0.01$ (Meyerhof, 1979; Meyerhof and Yalcin, 1993). The batter piles can be classified into two categories depending on the acting load, namely the positive and negative piles. The positive batter pile has horizontal load acting in the opposite direction to the batter, while the negative batter pile has horizontal load acting in the same direction of the batter as shown in Fig. 1.

Earlier extensive theoretical and experimental studies have been made to analyse the behaviour of single vertical and batter piles in various soils under various loads, for example Brinch-Hansen (1961), Murthy (1964), Kubo (1965), Award and Petrasovits (1968), Meyerhof and Ranjan (1973), Meyerhof (1979), Poulos and Davis (1980), Meyerhof et al. (1981), Takahashi (1985), Meyerhof and Yalcin (1993), Manoppo and Koumoto (1998) and Khari et al. (2014). All the above research studies have indicated that the behaviour of the batter piles is more complicated than

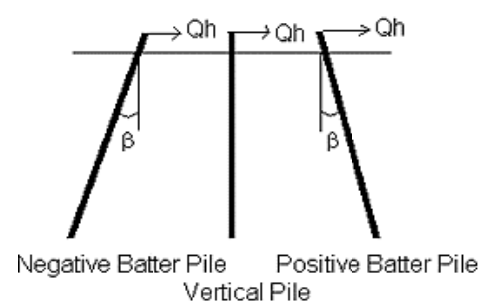

Fig. 1: General types of batter piles compared to the vertical plie (Manoppo and Koumoto, 1998)

the vertical piles, thus, further investigation is still needed for gaining a better understanding about the analysis of such piles.

This research was intended to provide experimental data concerning the behaviour of single battered piles under lateral soil movement in sands. The laboratory tests were preferred over the field test methods because of their cost-effectiveness and technical simplicity.

\section{EXPERIMENTAL SETUP}

The experimental setup primarily consists of a specially designed wooden box, a loading system and a measurement system. A sandy soil was used in the laboratory model, where a single pile or pile group was installed. The loading system allows lateral soil movement to be applied to the single pile or pile group embedded in the sand. The measurement system

Corresponding Author: Wisam Alawadi, University of Salford, Salford, M5 4WT, UK

This work is licensed under a Creative Commons Attribution 4.0 International License (URL: http://creativecommons.org/licenses/by/4.0/). 


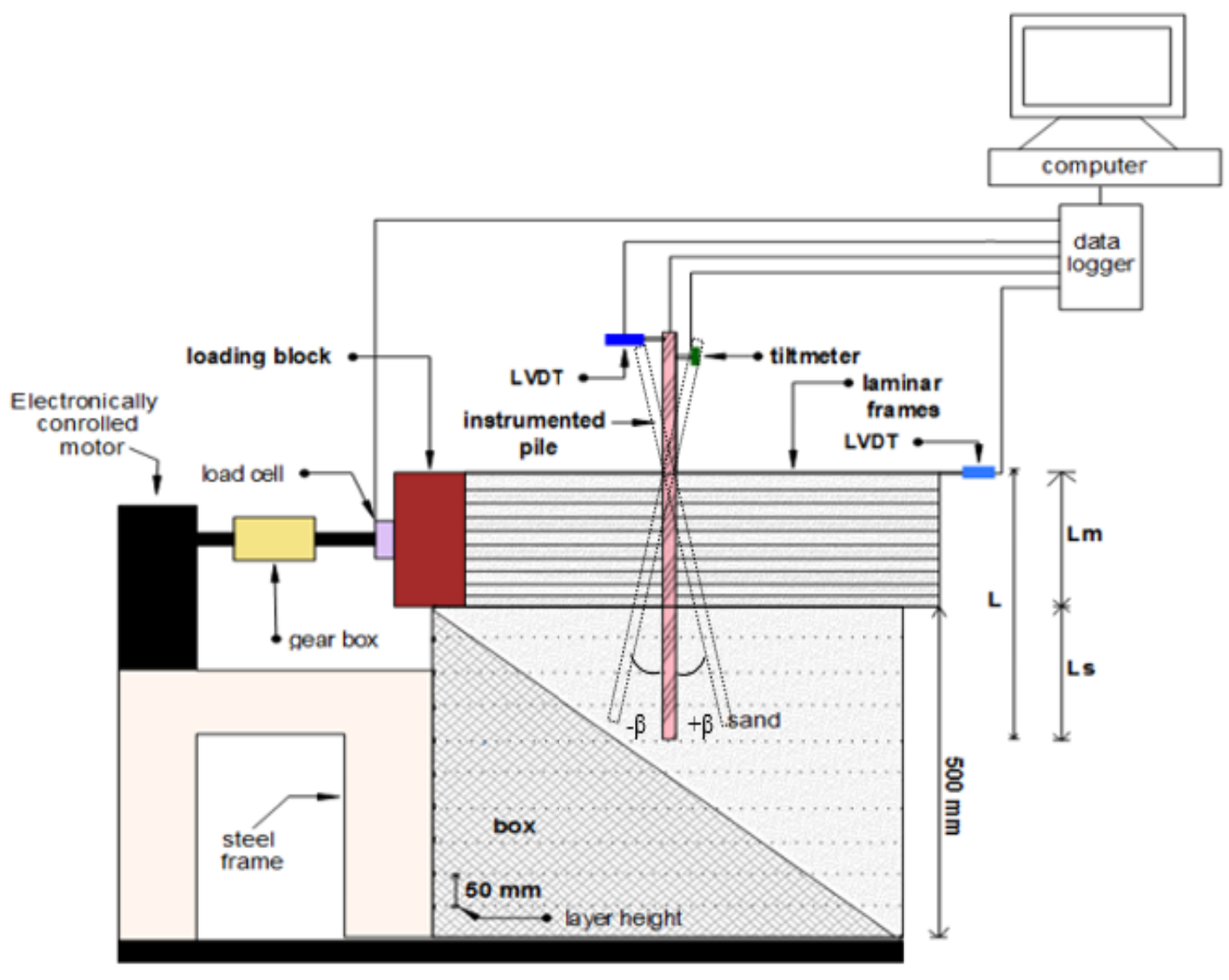

(a)

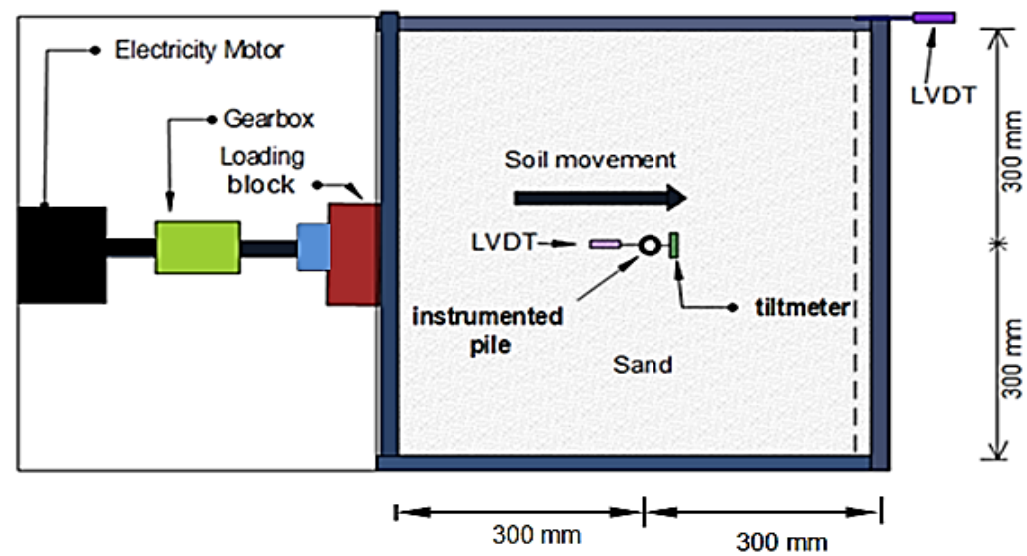

(b)

Fig. 2: Schematic diagram of test box: (a) Elevation view and (b) Top view

consists of a data acquisition system, pile instrumentation, LVDTs and a Tiltmeter. The experimental data obtained from the measurement system provided the information that assisted to investigate the effect of lateral soil movement on single piles and pile group. The testing box, sand properties and model piles instrumentation are briefly presented in the following sections.
Testing box: The internal dimensions of the box are $600 \mathrm{~mm}$ by $600 \mathrm{~mm}$ and $700 \mathrm{~mm}$ in height. A schematic diagram of the wooden box and the loading system used in the experiments are shown in Fig. 2. The upper part of the box is made of a series of $20 \mathrm{~mm}$ thick square laminar timber frames. These frames have smooth upper and lower surfaces to facilitate sliding of the frames in the horizontal direction. The frames, 
Res. J. Appl. Sci. Eng. Technol., 16(1): 24-29, 2019
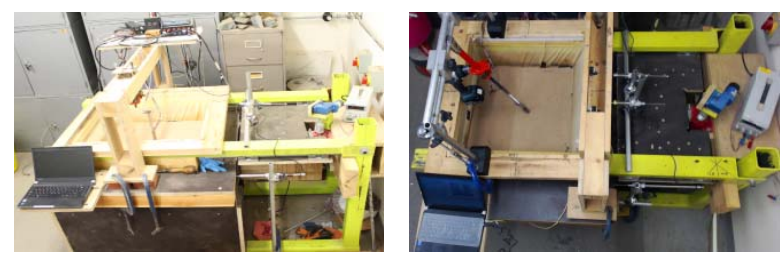

(a) Test box
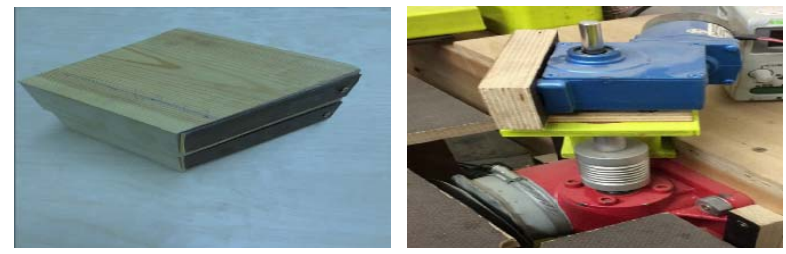

(b) Loading system

Fig. 3: Photos showing the test box (a) and lateral loading system (b)

which are allowed to slide horizontally, contain the "moving layer of soil" of thickness $\mathrm{L}_{\mathrm{m}}\left(\mathrm{L}_{\mathrm{m}} \leq 200 \mathrm{~mm}\right)$.

The lower section of the box comprises a $500 \mathrm{~mm}$ high fixed timber (plywood) box. Moreover, changing the number of movable frames in the upper section, the thicknesses of the stable $\left(\mathrm{L}_{\mathrm{s}}\right)$ and moving layers $\left(\mathrm{L}_{\mathrm{m}}\right)$ are varied accordingly. The inner face of the test box was marked at $50 \mathrm{~mm}$ intervals to assist the accurate formation of sand stacking inside the test box during the tests. The dimensions of the test box have been chosen according to previous researches taking into consideration the boundary conditions influence of the test box (Khari et al., 2014; Al-abboodi and Sabbagh, 2018). Figure 3 shows the test box used in this study.

The lateral loading system consists of a loading block (Fig. 3b) and a screw jack connected to an electronically controlled motor with a maximum capacity of $25 \mathrm{KN}$. The loading block is used to apply lateral force on the laminar frames, which is made into triangular and rectangular shape to impose the corresponding soil movement profiles. Throughout all the test programmes, the rate of movement of the upper box (the laminar frames) is controlled by the motor screw jack loading system. The loading rate of 3 $\mathrm{mm} / \mathrm{min}$ was chosen in this study according to the model tests adopted by Poulos et al. (1995).

Soil properties: The model piles were embedded in dry sand of medium to fine particles size. The sand properties were obtained from various laboratory tests conducted on the sand in accordance with BS specifications. The gradation curve of the sand used in the experiments is shown in Fig. 4, while the properties of the sand are given in Table 1.

Model piles: Three types of model piles were fabricated from a hollow circle aluminium tube with
Table 1: Properties of the model sand soil

\begin{tabular}{lll}
\hline Property & Value & Specification \\
\hline Specify grafity $\mathrm{G}_{\mathrm{s}}$ & 2.7 & BS 1377-2 \\
Effective size $\mathrm{D}_{10} \mathrm{~mm}$ & 0.15 & BS 1377-2 \\
$\mathrm{D}_{30} \mathrm{~mm}$ & 0.21 & BS 1377-2 \\
Mean grain size $\mathrm{D}_{50} \mathrm{~mm}$ & 0.29 & BS 1377-2 \\
$\mathrm{D}_{60} \mathrm{~mm}$ & 0.31 & BS 1377-2 \\
Particle size range mm & $0.063-1.18$ & Sieve analysis \\
Coefficient of uniformity $\mathrm{C}_{\mathrm{u}}$ & 2.06 & ASTM \\
Coefficient of curvature $\mathrm{C}_{\mathrm{c}}$ & 0.95 & ASTM \\
Soil classification & SP & USCS \\
Soil description & Poorly graded & \\
& sand & \\
Max. dry unit weight $\mathrm{kN} / \mathrm{m}^{3}$ & 16.63 & BS 1377-4 \\
Min. dry unit weight $\mathrm{kN} / \mathrm{m}^{3}$ & 14.0 & BS 1377-4 \\
Max. void ratio & 0.9 & BS 1377-4 \\
Min void ratio & 0.6 & BS 1377-4 \\
Dry unit weight $\left(\gamma_{\mathrm{d}}\right)$ & $14.7 \mathrm{KN} / \mathrm{m}^{3}$ & \\
Angle of internal friction $(\Phi)$ & $34^{\circ}$ degree & BS 1377-7 \\
\hline
\end{tabular}

Table 2: Pile dimensions and its material properties

\begin{tabular}{ll}
\hline Pile details & Value \\
\hline Outside diameter $(\mathrm{mm})$ & 16,20 and 25 \\
Wall thickness $(\mathrm{mm})$ & 1.2 \\
Type of pile & Aluminium \\
Modulus of Elasticity $(\mathrm{MPa})$ & 70000 \\
Density $(\gamma \mathrm{a})\left(\mathrm{kN} / \mathrm{m}^{3}\right)$ & 27 \\
Poisson's Ratio $(\mathrm{va})$ & 0.33 \\
\hline
\end{tabular}

Poisson's Ratio (va)

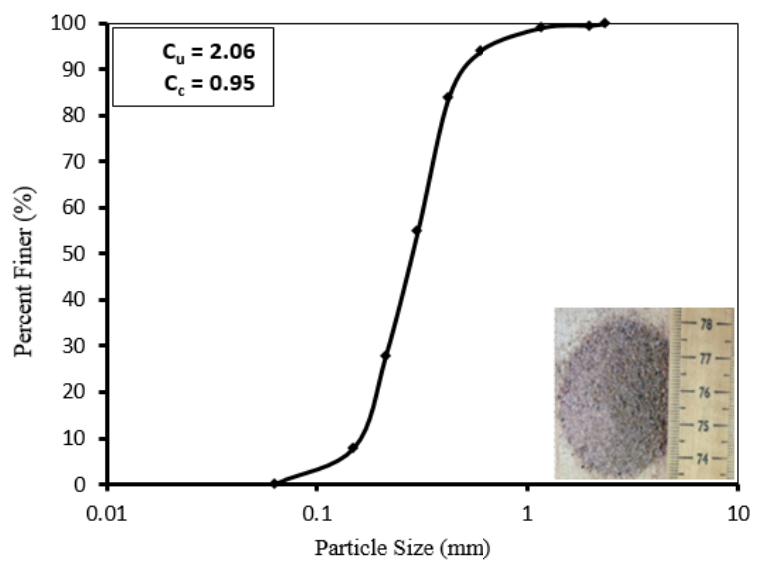

Fig. 4: Gradation curve of the sand

outer diameter of 16,20 and $25 \mathrm{~mm}$ and a wall thicknesses of $1.2 \mathrm{~mm}$. The total length of the model pile is $350 \mathrm{~mm}$ with variable embedded pile length depending on the test type. Table 2 shows the dimensions and the material properties of the piles used. The piles were instrumented with six strain gauges to measure the bending moment along the embedded lengths numbered from SG1 to SG6, as shown in Fig. 5. Each strain gauge was glued on the model pile surface at a vertical interval of $50 \mathrm{~mm}$. The gauges were covered with clear heat shrink tube along the entire length of the pile to protect them from damage. The model pile surface has been made rough by gluing it with dry sand particles to simulate the contact surface that would be generated between a concrete pile and the soil in actual cases. 


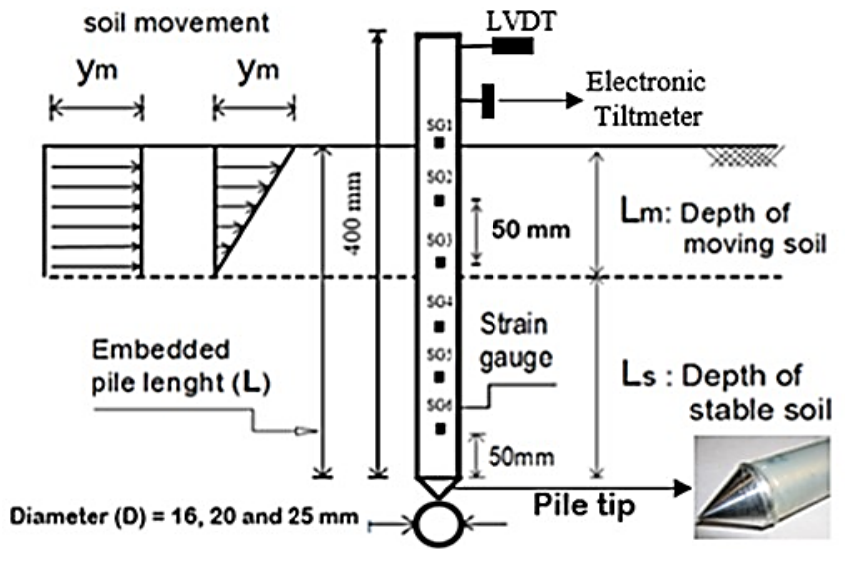

(a)

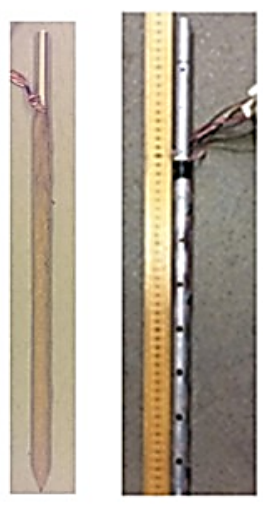

(b)

Fig. 5: Schematic diagram of a pile subjected to rectangular and triangular loading block; (a) Schematic diagram of model pile and (b) Instrumented model pile

\section{RESULTS AND DISCUSSION}

Effect of batter angle on bending moment: In order to investigate the influence of batter angle $(\beta)$ on the batter pile response, five tests were conducted on the 16 $\mathrm{mm}$ diameter pile and subjected to rectangular loading block at sand density $(\gamma)$ of $15.5 \mathrm{KN} / \mathrm{m}^{3}$ with different angle of inclination $(\beta=0, \pm 10$ and \pm 20$)$. The box was filled with sand to the top. Hence the pile length in the upper "moving" sand layer $\left(\mathrm{L}_{\mathrm{m}}\right)$ was $150 \mathrm{~mm}$, while that in the lower "stable" sand layer $\left(\mathrm{L}_{\mathrm{s}}\right)$ was $150 \mathrm{~mm}$.

Figure 6 shows the response of the batter pile in terms of bending moment measured at $25 \mathrm{~mm}$ of box displacement (y) for the five tests. From the figure, it can be seen that the shape of bending moment profile for all tests are almost similar (parabolic shape) and the values of the bending moments developed along the embedded length of the pile were all positive. The

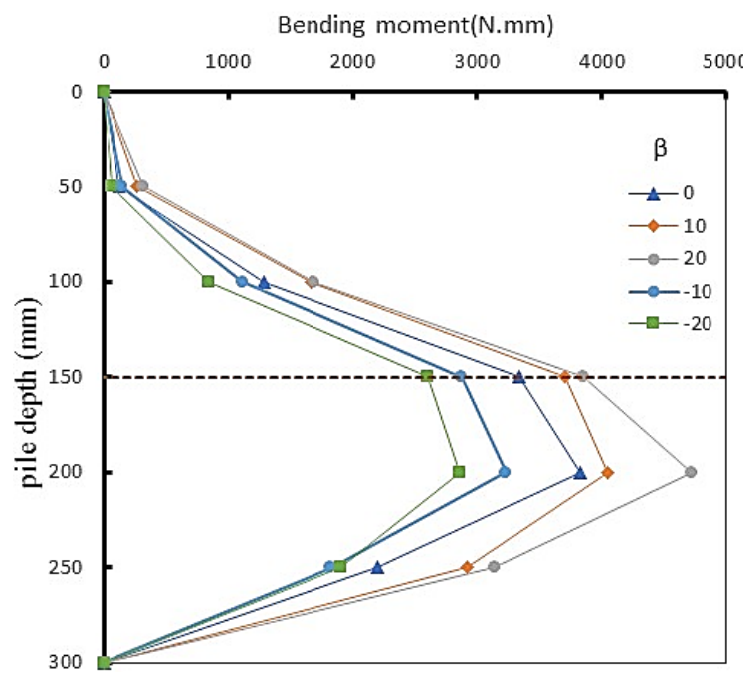

Fig. 6: Bending moment profiles with different values of $\beta$ and $\mathrm{y}=25 \mathrm{~mm}$

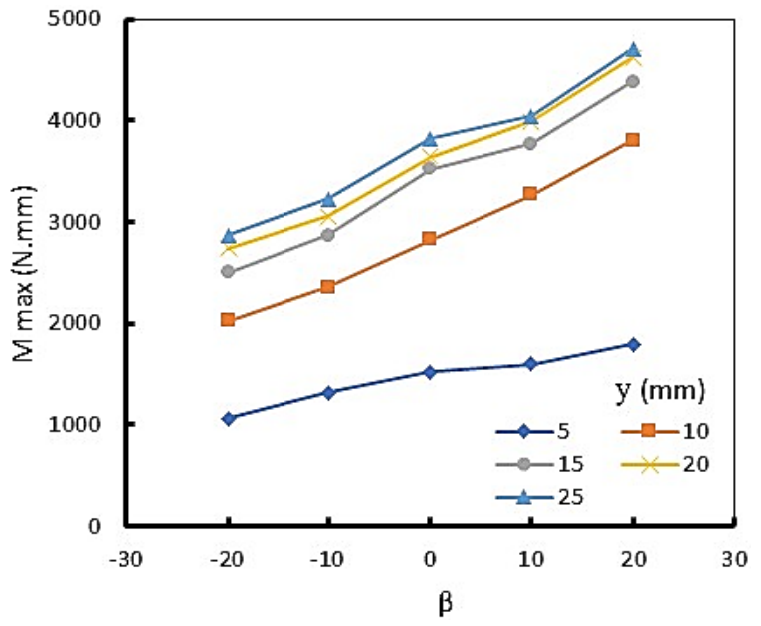

Fig. 7: $M_{\max }$ of batter pile with different values of $(\beta)$

results also show that the maximum bending moment $\left(\mathrm{M}_{\max }\right)$ occurs at a depth of $200 \mathrm{~mm}$, i.e., about $0.67 \mathrm{~L}$.

The variation of $\mathrm{M}_{\max }$ for all tests, at the depth of the maximum moment $\left(\mathrm{d}_{\max }=200 \mathrm{~m}\right)$ with the batter angle are shown in Fig. 7. It can be seen that the $M_{\max }$ measured at $\beta=+20$ was the greatest for different stages of soil movement (y). Conversely, $\mathrm{M}_{\max }$ measured at $\beta=-20$ was the smallest.

The relationship between the $\mathrm{M}_{\max }$ and lateral soil displacement (y) for various batter angles $(\beta)$ is shown in Fig. 8. The results indicate that at $y \leq 10 \mathrm{~mm}$ the magnitude of the $\mathrm{M}_{\max }$ increases linearly as the $\mathrm{y}$ increases. For all test cases, the $\mathrm{M}_{\max }$ reaches its peak at $y>20 \mathrm{~mm}$ and approximately remains constant in regardless of batter angle.

Effect of batter angle on shear force and soil reaction: Figure 9 demonstrates the response of the batter piles in terms of the shear force measured at 25 $\mathrm{mm}$ of box displacement (y) for all tests. According to 


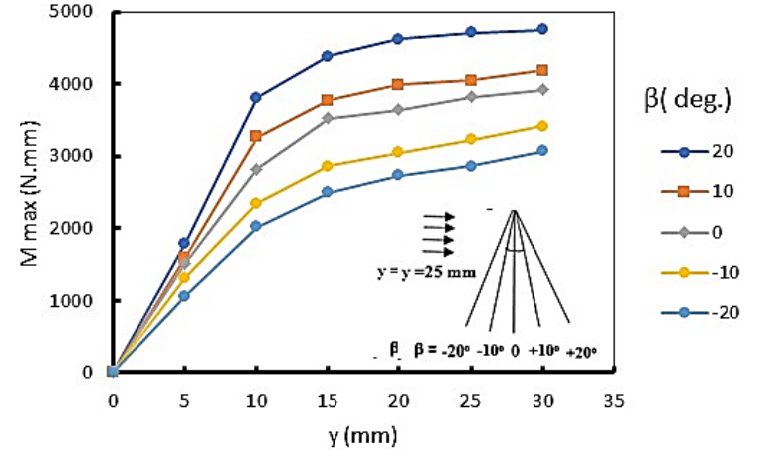

Fig. 8: $\mathrm{M}_{\max }$ of batter pile with different values of (y)

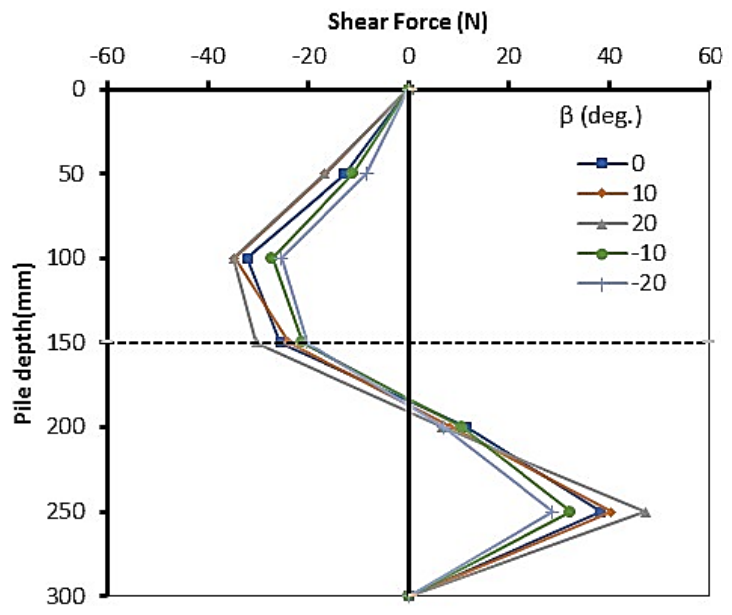

Fig. 9: Shear force profiles with different values of $\beta$ and $y=$ $25 \mathrm{~mm}$

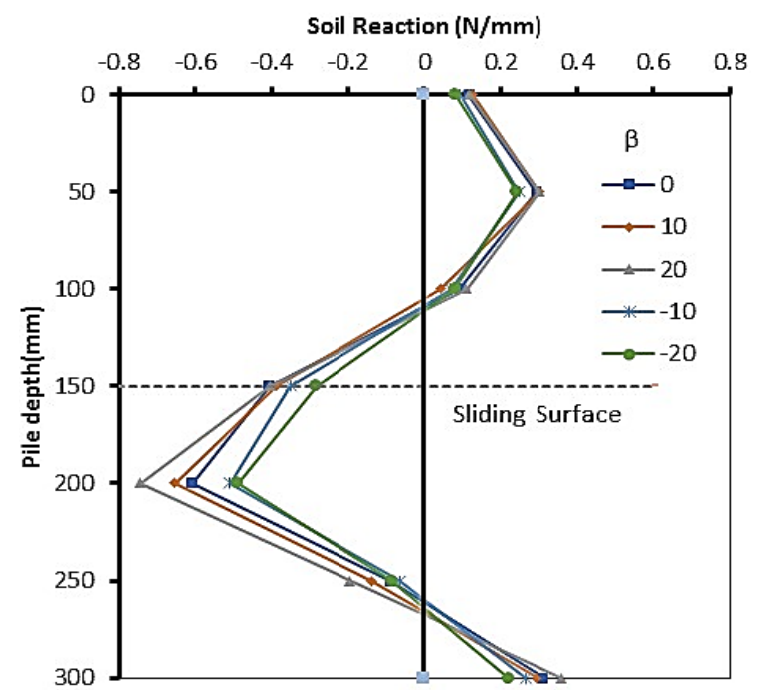

Fig. 10: Soil reaction profiles with different values of $\beta$ and $y$ $=25 \mathrm{~mm}$

the case of $\beta=0$. The test result on vertical pile obtained in this study were reasonably consistent with those obtained by Poulos et al. (1995) and Guo and Qin (2010). It can also be observed that the largest negative shear force develops at a depth of $100 \mathrm{~mm}(0.33 \mathrm{~L})$, while the maximum positive shear force occurs at a depth of $250 \mathrm{~mm}(0.83 \mathrm{~L})$.

The soil reaction profiles of the five different batter angles $(\beta)(0, \pm 10$ and \pm 20$)$ are shown in Fig. 10 . In this figure, the piles are subjected to soil movement of $\mathrm{y}=$ $25 \mathrm{~mm}$. The results show that the maximum soil resistance occurs at the depth of $200 \mathrm{~mm}(0.67 \mathrm{~L})$. The figure also indicates that the soil reaction within the moving soil layer $\left(\mathrm{L}_{\mathrm{m}}\right)$ has an arc shape and reaches its maximum at a depth of approximately $50 \mathrm{~mm}\left(\mathrm{~L}_{\mathrm{m}} / 3\right)$. In the vicinity of the sliding surface $(115 \mathrm{~mm}$ below soil surface), there was a remarkable change in the reaction distribution (sign change). This change is expected because both moving and stationary soil layers have opposite actions on the pile shaft. It should be noted that the batter pile with $\beta=+20$ exhibits the largest soil reaction compared to the others.

Effect of Batter Angle on Deflection and Rotation of Pile: Figure 11 and 12 show the deflection and rotation

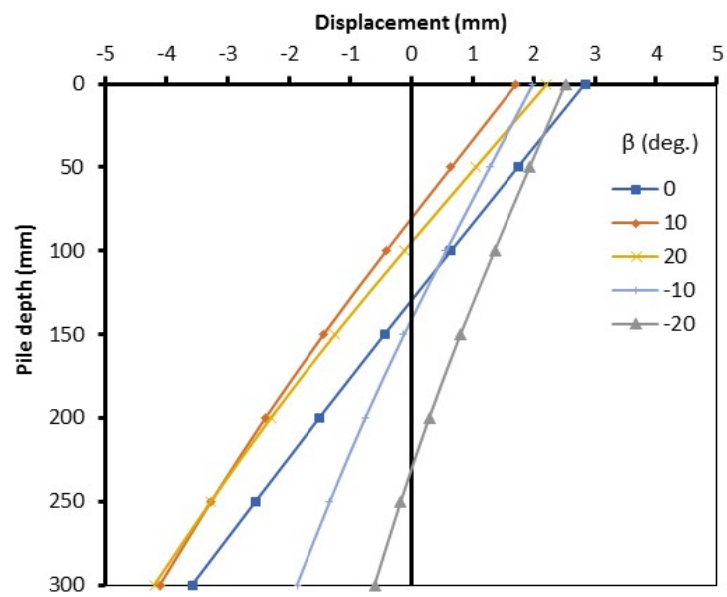

Fig. 11: The pile deflection profile with different values of $\beta$ and $\mathrm{y}=25 \mathrm{~mm}$.

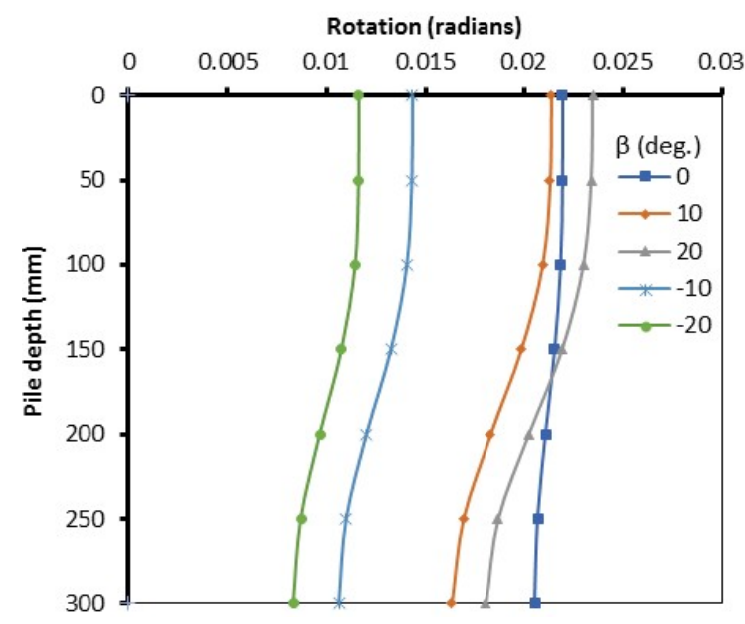

Fig. 12: The pile rotation profile with different values of $\beta$ and $\mathrm{y}=25 \mathrm{~mm}$ 
profiles at $\mathrm{y}=25 \mathrm{~mm}$ for the piles with different values of $\beta$. The results in Fig. 11 show that the pile deflection at the soil surface for various batter angles is generally less than the corresponding lateral soil movement (y). This may suggest that the moving sand is flowing around the pile. For instance, in test with $\beta=0$, the pile displacement at the ground surface is about $2.4 \mathrm{~mm}$ at $\mathrm{y}$ $=25 \mathrm{~mm}$.

Figure 12, it can be observed that the shapes of the pile rotation profiles are similar for all the tests. The results of the rotation profiles indicate that the pile behaves as a rigid element where the rotation angle remains positive for the entire pile length with small differences between the top and bottom section of the pile. From the figure, it is also clear that for the test with $\beta=+20$, the rotation at the soil surface is about $100 \%$ higher than that with $\beta=-20$.

\section{CONCLUSION}

A number of tests has been conducted on models of single batter piles. From these tests, the following conclusions regarding the batter pile behaviour were observed:

1. Pile batter angle ( $\beta$ ) has shown a significant effect on the induced bending moment with the magnitude of the maximum bending moment $\left(\mathrm{M}_{\max }\right)$ fluctuating with $\beta$ values. According to the results, the highest $M_{\max }$ was observed at $\beta=+10$, whereas the least $M_{\max }$ was recorded when $\beta=-20$. It was also found that the shape of the bending moment profile is a single curvature for all values of $(\beta)$.

2. It was found that the shear force profiles for batter piles of different values of $\beta$ are similar in the shape to the corresponding profiles measured for the vertical pile test. The largest negative shear force was found to occur at a depth equal to 0.33 of the pile length, while the maximum positive shear force occurs at a depth of $0.83 \mathrm{~L}$.

3. The results of the pile deflection indicated that the pile deflection at the soil surface for various batter angles is generally less than the corresponding lateral soil movement (y). The results of the rotation profiles have shown that the rotation angle of the pile remains positive along the entire length, suggesting that the pile acts as a rigid element.

\section{REFERENCES}

Al-abboodi, I. and T.T. Sabbagh, 2018. Model tests on piled raft subjected to lateral soil movement. Int. J. Geotech. Eng., 12(4): 357-367.
Award, A. and G. Petrasovits, 1968. Considerations on the bearing capacity of vertical and batter piles subjected to forces in different directions. Proceedings of 3rd Conference on Soil Mechanics, Budapest, pp: 483-497.

Brinch-Hansen, J., 1961. The Ultimate Resistance of Rigid Piles against Transversal Forces. Geoteknisk Instit., Bull. No. 28, Copenhagen.

Guo, W.D. and H.Y. Qin, 2010. Thrust and bending moment of rigid piles subjected to moving soil. Can. Geotech. J., 47(2): 180-196.

Khari, M., K.A. Kassim and A. Adnan, 2014. Development of curves of laterally loaded piles in cohesionless soil. Sci. World J., 2014: 1-8.

Kubo, K., 1965. Experimental study of the behaviour of laterally loaded piles. Proceedings of the 6th International Conference on Soil Mechanics and Foundation Engineering, Montreal, 2: 275-279.

Manoppo, F.J. and T. Koumoto, 1998. Fitting method for determining the ultimate bearing capacity of flexible batter piles in homogeneous sand under horizontal loads. Trans. Japanese Soc. Irrigat. DrMeyerhof, G.G. and A.S. Yalcin, 1993. Behaviour of flexible batter piles under inclined loads in layered soil. Can. Geotech. J., 30(2): 247256.

Meyerhof, G.G., S.K. Mathur and A.J. Valsangkar, 1981. Lateral resistance and deflection of rigid walls and piles in layered soils. Can. Geotech. J., 18(2): 159-170.

Murthy, V.N.S., 1964. Behaviour of batter piles subjected to lateral loads. Ph. D. Thesis, Indian Institute of Technology, Kharagpur, India.

Poulos, H.G. and E.H. Davis, 1980. Pile Foundation Analysis and Design. John Wiley and Sons, New York.

Poulos, H.G., L.T. Chen and T.S. Hull, 1995. Model tests on single piles subjected to lateral soil movement. Soils Foundat., 35(4): 85-92.

Takahashi, K., 1985. Bending of a batter pile due to ground settlement. Soils Foundations, 25(4): 7591ain. Reclamat. Eng., 197: 71-78.

Meyerhof, G.G., 1979. Soil-structure interaction and foundations. General Report, proceeding of the 6th Panamerican Conference on Soil Mechanics, Lima, 1: 109-140.

Meyerhof, G.G. and G. Ranjan, 1973. The bearing capacity of rigid piles under inclined loads in sand. II: Batter piles. Canadian Geotech. J., 10(1): 71-85. 